\title{
Pembangunan Sistem Monitoring Debitur Dengan Menggunakan Arsitektur Three-Tier (Studi Kasus : Bank Umum Di Indonesia)
}

\author{
I Gede Aditya Wiratama, Bekti Cahyo Hidayanto, Feby Artwodini Muqtadiroh \\ Departemen Sistem Informasi, Fakultas Teknologi Informasi, Institut Teknologi Sepuluh Nopember (ITS) \\ e-mail: igedeadityawiratama@gmail.com, bekticahyo@gmail.com, feby.artwodini@gmail.com
}

\begin{abstract}
Abstrak-Bank berfungsi sebagai lembaga penyalur antara kelompok masyarakat pemilik dana dengan masyarakat yang membutuhkan dana. Bank menghimpun dana dari masyarakat dalam bentuk tabungan, giro, deposito maupun bentuk simpanan yang lain. Dana yang terkumpul tersebut akan disalurkan dalam bentuk pinjaman atau kredit. Kredit merupakan penyediaan dana atau tagihan yang berdasarkan pada kesepakatan pinjam-meminjam antara penyedia dana dengan pihak peminjam atau yang membutuhkan dana. Kompensasi yang diberikan oleh pihak peminjam dapat berupa bunga, imbalan atau bagi hasil maupun kesepakatan lain yang disetujui bersama antara pihak bank dan peminjam. Dalam mengambil keputusan terkait kredit yang diajukan calon debitur, bank melakukan analisis dari berbagai data. Sistem monitoring debitur merupakan sistem yang penulis tawarkan untuk menyimpan data secara terpusat sehingga dapat diakses kapan dan di mana saja dengan mudah. Sistem di rancang dengan menggunakan arsitektur three-tier. Hal ini bertujuan agar tampilan aplikasi dapat dikembangkan dalam bahasa lain, namun tetap memiliki aturan yang baku.
\end{abstract}

Kata Kunci-Bank, kredit, kredit wholesale, system monitoring, three-tier architecture.

\section{PENDAHULUAN}

K REDIT merupakan penyediaan dana atau tagihan yang berdasarkan pada kesepakan pinjam-meminjam antara penyedia dana dengan pihak peminjam atau yang membutuhkan dana atas dasar kepercayaan. Dalam hal ini, penyedia dana adalah bank sehingga mewajibkan pihak peminjam dana untuk mengembalikan dana dalam kurun waktu beserta kompensasi yang telah ditentukan. Kompensasi yang diberikan oleh pihak peminjam dapat berupa bunga, imbalan atau bagi hasil maupun kesepakatan lain yang disetujui bersama antara pihak bank dan peminjam [1].

Pertumbuhan kredit di Indonesia relatif besar bila dibandingkan dengan negara lain di Asia. Pada Tahun 2016 terjadi pertumbuhan kredit mendekati kisaran 9 persen. Dimana hal tersebut sesuai dengan target dari bank sentral yaitu pertumbuhan kredit berkisar antara 7 hingga 9 persen [2]. Dengan pertumbuhan yang cukup besar tersebut, kredit menjadi salah satu aktivitas utama dalam bisnis perbankan.

Dalam mengambil keputusan terkait kredit yang diajukan calon debitur bank melakukan analisis. Bank mengumpulkan seluruh data dan informasi terkait calon debitur untuk di analisis. Untuk analisis kredit korporasi, setidaknya terdapat beberapa data yang diperlukan oleh bank yaitu identitas calon debitur, data dan informasi keuangan, daftar agunan atau jaminan dari pihak calon debitur, hasil IDI Bank Indonesia, informasi mengenai grup calon debitur, laporan hasil kunjungan ke perusahaan calon debitur [1].

Data dan informasi merupakan hal yang sangat penting Karena informasi merupakan aset bagi suatu organisasi atau bisnis. Dalam studi kasus ini data dan informasi yang dimiliki oleh perusahaan adalah data dan informasi milik calon debitur. Data dan informasi tersebut harus dilindungi. Perlindungan terhadap data dan informasi terdiri dari beberapa aspek, yaitu confidentiality, integrity, dan availability [1].

Saat ini Bank Mandiri masih menggunakan spreadsheet sebagai sarana untuk menyimpan data dan informasi debitur. Untuk saling bertukar data dan informasi yang ada staff Bank Mandiri menggunakan media penyimpanan yang dimiliki. Hal ini menyebabkan kesulitan ketika harus mencari dimana posisi data dan informasi terkakhir dari suatu debitur berada. Serta menyebabkan mudahnya data untuk tersebat ke pihak yang tidak berkepentingan. Padahal saat ini Bank Mandiri sudah memiliki server yang terpusat yang terhubung dengan jaringan internal di seluruh gedung milik Bank Mandiri yang terdapat di Indonesia.

Dari apa yang telah penulis sebutkan sebelumnya, dapat disimpul terdapat beberapa masalah yang dialami pihak Bank Mandiri dalam proses memberikan kredit kepada segment korporasi. Masalah pertama adalah, bagaimana setiap bagian dari Bank Mandiri yang berkaitan dengan pengambilan keputusan kredit bisa mendapatkan data dan informasi terakhir terkait debitur dalam waktu segera. Masalah kedua adalah bagaimana agar data dan informasi terkait calon debitur Bank Mandiri tidak tersebar kepada pihak yang tidak memiliki kepentingan. Dan masalah yang terakhir adalah bagaimana melakukan pengasawan terhadap debitur dengan mudah dan cepat.

Untuk menyelesaikan permasalah yang telah disebutkan, penulis memiliki suatu gagasan untuk membuat sistem berbasiskan website. Sistem yang ingin penulis buat merupakan sistem yang akan membantu pihak Bank Mandiri untuk menyimpan semua data dan informasi terkait calon debitur yang ada dalam satu tempat sehingga data dan informasi terakhir dapat di akses dengan segera dan dari manapun dengan aman. Dan untuk dapat memanfaatkan server milik Bank Mandiri, maka penulis harus 
menyesuaikan dengan arsitektur server yang ada, yaitu arsitektur tiga tingkat atau three-tier architecture.

\section{TINJAUAN PUSTAKA}

\section{A. Bank}

Bank merupakan suatu lembaga keuangan yang berfungsi sebagai lembaga penyalur antara kelompok masyarakat pemilik dana dengan masyarakat yang membutuhkan dana atau dapat disebut sebagai financial intermediary. Pemilik dana menyimpan dana yang dimiliki di bank dalam bentuk tabungan, deposito maupun simpanan lainnya. Dana yang telah di kumpulkan tersebut disalurkan kepada masyarakat yang membutuhkan dana dalam bentuk kredit. Hal ini sesuai dengan Undang - Undang No. 10 tahun 1998, dimana bank adalah badan usaha yang menghimpun dana dari masyarakat dalam bentuk simpanan dan menyalurkan kepada masyarakat dalam bentuk kredit dan/atau bentuk - bentuk lainnya dalam rangka meningkatkan taraf hidup rakyat [3].

\section{B. Kredit Wholesate}

Kredit wholesale dapat juga disebut sebagai kredit segmen korporasi. Kredit pada segmen korporasi memiliki karakteristik dan struktur pembiayaan yang kompleks. Pada umumnya kredit pada segment ini berdasarkan pada arus kas dan fasilitas atau jaminan sesuai kebutuhan bisnis masingmasing calom debitur [1].

Kredit yang diberikan kepada debitur pada segmen korporasi memiliki jumlah yang besar. Karena jumlah kredit yang besar tersebut, bank melakukan pengawasan yang sangat ketat terhadap calon debitur. Selain pengawasan yang ketat, bank juga membutuhkan waktu yang cukup lama daripada memproses kredit yang diberikan kepada reatail maupun consumer [1].

Dalam proses kredit yang di berikan kepada wholesalte terdapat perhitungan data, yaitu:

$$
\text { Nilai Kecukupan }=\frac{\text { stok } / \text { persediaan }+ \text { piutang }+k a s}{\text { kredit }}
$$

Nilai $C A=$ Cash + Trade Receivables + Other Receivables + Inventory + Prepaid Expenses + Prepaid Taxes + SundryCA

$$
\begin{aligned}
& \text { Nilai } C L=S T D-\text { Bank }(\text { existing })+\text { Current Portion } \\
& \quad+\text { Trade payables }+ \text { Accrued Expenses } \\
& + \text { Tax Payables }+ \text { Deferred Income } \\
& + \text { Sundry CL } \\
& \text { Nilai } C R=\frac{\text { Nilai } C A}{\text { Nilai } C L} \times 100 \% \\
& \text { Nilai NPM }=\frac{\text { laba }}{\text { sales }} \times 100 \% \\
& \text { Debt service coverage }=\frac{\text { ebitda }}{\text { angsuran }+ \text { bunga }} \times 100 \%
\end{aligned}
$$

\section{Sistem Informasi}

Sistem informasi adalah sekumpulan manusia dan mesin yang terpadu dengan tujuan untuk menyajikan informasi yang mendukung fungsi operasi, manajemen, dan pengambilan keputusan dalam sebuah organisasi. Informasi adalah data yang telah diolah menjadi bentuk yang berguna dan memiliki nilai bagi penerimanya [4].

\section{Three-tier architecture}

Arsitektur Three Tier merupakan pengembangan dari arsitektur Client Server. Arsitektur Client Server adalah arsitektur jaringan yang memisahkan client (umumnya merupakan GUI) dengan server. Server dapat memberikan data atau informasi sesuai yang diminta oleh client [5].

Arsitektur three tier terdiri dari 3 bagian, yaitu:

1. Presentation layer

Layer pertama ini disebut user interface. Presentation layer merupakan layer yang berinteraksi secara langsung, memberikan informasi yang dapat dibaca dan dipahami dengan mudah oleh pengguna.

2. Logical layer

Logical layer merupakan penghubung dari 2 layer lainnya. Logical layer membuat keputusan logic, dan memproses data yang melaluinya.

3. Data layer

Merupakan layar di mana data tersimpan. Informasi yang diminta dari presentation layer akan diambil dari data layer.

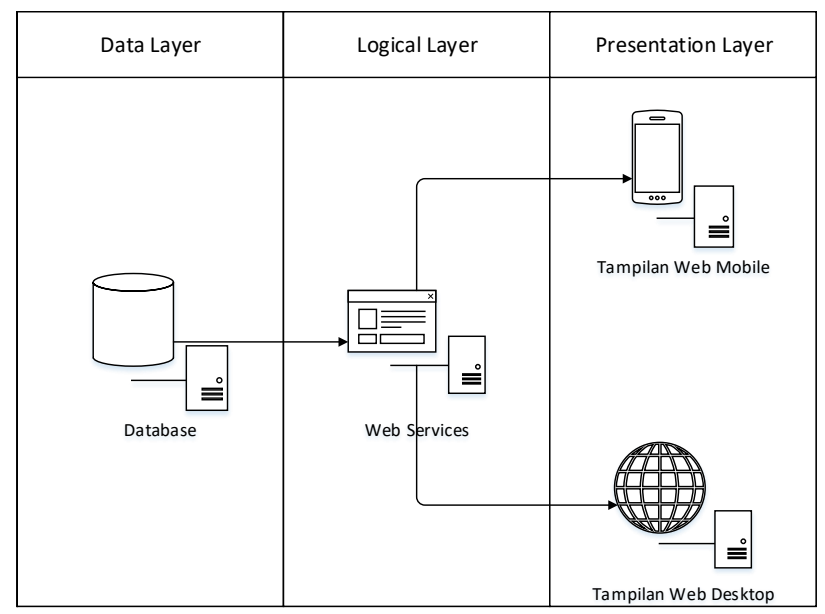

Gambar 1. Arsitektur three tier

\section{E. RESTful Web Services}

Representational State Transfer atau lebih dikenal dengan Rest merupakan arsitektur yang dapat menentukan tiap keadaan dengan spesifik. RESTful web services dibangun untuk bekerja dengan baik di web. Dalam gaya penulisan REST, data dan fungsi dianggap sumber daya dan diakses menggunakan Uniform Resource Identifier (URI) [6].

Terdapat beberapa prinsip agar RESTful dapat berjalan dengan mudah, ringan dan cepat [6]:

- Identifikasi sumber daya melalui URI

- Antarmuka yang seragam

- Pesan yang mendeskripsikan diri sendiri

- Interaksi melalui hyperlink

\section{F. JavaScript Object Notation (JSON)}

JavaScript Object Notation atau yang lebih dikenal dengan JSON merupakan format pertukaran data yang ringan. JSON memiliki kemudahan untuk di tulis maupun dibaca oleh manusia, dan cukup mudah untuk di terjemahkan dan dibuat oleh mesin. JSON merupakan bahasa yang berbasiskan pada 
bahasa pemrograman JavaScript. JSON adalah sebuah format penulisan bahasa yang sepenuhnya berdiri sendiri, sehingga menjadikan JSON sebagai sebuah pertukaran data yang ideal [7].

JSON terdiri dari dua struktur. Struktur pertama adalah pasangan nama/nilai, dalam bahasa pemrograman lain dapat dianggap sebagai objek. Struktur kedua adalah daftar nilai terurutkan, dalam bahasa pemrograman lain direalisasikan sebagai array, daftar, atau urutan [7].

\section{G. $M y S Q L$}

MySQL adalah database open source yang paling banyak digunakan saat studi ini dibuat, dengan nilai 1347,71 [8]. MySQL mampu untuk memberikan kinerja yang tinggi dalam skalabilitas yang besar dengan biaya yang efektif. MySQL Community Edition merupakan edisi yang bisa di dapatkan dengan gratis [9].

\section{H. DESAIN APLIKASI}

\section{1) Kebutuhan Fungsional}

Pada proses ini penulis akan melakukan Analisa terkait apa saja kemampuan yang dimiliki oleh system. Kemampuan yang dimaksud adalah layanan yang akan diberikan oleh sistem guna memenuhi kebutuhan pengguna. Kebutuhan fungsional sistem akan ditulis dalam suatu kode unik besert deskripsi singkat terkait kebutuhan tersebut. Berikut Kebutuhan Fungsional Sistem:

Tabel 1.

Kebutuhan Fungsional Sistem

\begin{tabular}{|c|c|}
\hline FR-101 & $\begin{array}{l}\text { Setiap pengguna harus memiliki akun yang diamankan } \\
\text { dengan username dan password. }\end{array}$ \\
\hline FR-102 & $\begin{array}{l}\text { Sistem hanya menampilkan data sesuai dengan level } \\
\text { pengguna saat masuk ke dalam sistem }\end{array}$ \\
\hline FR-201 & $\begin{array}{l}\text { Sistem dapat menampilkan rincian informasi mengenai } \\
\text { debitur, yakni: data profil debitur, data OTS, data } \\
\text { covenant data financial ratio }\end{array}$ \\
\hline FR-202 & $\begin{array}{l}\text { Sistem menyediakan fungsi untuk menambah dan } \\
\text { mengubah informasi debitur, yakni: data debitur, data } \\
\text { OTS, data covenant data financial ratio }\end{array}$ \\
\hline FR-203 & $\begin{array}{l}\text { Sistem menyediakan fungsi menyetujui dan/atau } \\
\text { konfirmasi untuk data terkait debitur yang baru } \\
\text { ditambahkan dan/atau diubah. }\end{array}$ \\
\hline FR-301 & $\begin{array}{l}\text { Sistem dapat melakukan kalkulasi/perhitungan secara } \\
\text { tepat pada financial ratio }\end{array}$ \\
\hline FR-401 & Sistem dapat menampilkan daftar covenant \\
\hline FR-501 & $\begin{array}{l}\text { Data di dalam sistem dapat dibuatkan back-up untuk } \\
\text { mencegah kehilangan data }\end{array}$ \\
\hline
\end{tabular}

\section{2) Kebutuhan Non-Fungsional}

Kebutuhan non-fungsional merukapakan kebutuhan yang dapat mendukung dalam berjalannya sebuah sistem sehingga dapat digunakan oleh pengguna. Berikut kebutuhan nonfungsional sistem:

Tabel 2.

Kebutuhan Non-Fungsional Sistem

\begin{tabular}{ll} 
NFR-101 & $\begin{array}{l}\text { Sistem dapat diakses oleh } 300 \text { pengguna aktif secara } \\
\text { bersamaan }\end{array}$ \\
NFR-102 & $\begin{array}{l}\text { Sistem dapat digunakan selama } 7 \times 24 \text { jam dalam } \\
\text { seminggu. }\end{array}$ \\
NFR-201 & $\begin{array}{l}\text { Data yang terdapat di dalam sistem harus dipastikan } \\
\text { aman. }\end{array}$ \\
NFR-202 & $\begin{array}{l}\text { Sistem secara otomatis akan sign out ketika tidak } \\
\text { digunakan selama 30 menit }\end{array}$ \\
NFR-301 & $\begin{array}{l}\text { Sistem dapat diakses di mana pun dan kapan pun selama } \\
\text { terhubung dengan server dimana sistem terinstall }\end{array}$ \\
\hline \hline
\end{tabular}

\begin{tabular}{ll}
\hline NFR-302 & $\begin{array}{l}\text { Sistem dapat diakses dengan menggunakan berbagai } \\
\text { browser, baik itu pada perangkat desktop maupun } \\
\text { mobile. }\end{array}$ \\
\hline
\end{tabular}

\section{IMPLEMENTASI APLIKASI}

Pada bagian ini akan dijelaskan tahap implementasi dari aplikasi yang dibuat oleh penulis.

1) Data Layer

Pada data layer hanya terdapat database yang telah di desain dalam perancangan sistem. Database tidak dapat diakses secara langsung oleh pengguna. Adapun database dari sistem dapat di lihat dalam gambar berikut:

\begin{tabular}{|l|l|}
\hline Table & aktivitas \\
\hline$\square$ & cmb \\
$\square$ & covenant \\
$\square$ & debitur \\
$\square$ & financial_ratio \\
$\square$ & grup_debitur \\
$\square$ & konfigurasi \\
$\square$ & ots \\
$\square$ & user \\
9 tables
\end{tabular}

Gambar 2. Database dari system

\section{2) Logical Layer}

Pada logical layer terdapat API yang dapat diakses untuk melihat dan mengubah rincian data dalam database. Layer ini berguna bagi developer untuk menghubungkan database dengan presentation layer. Adapun daftar API dapat dilihat pada tabel berikut:

Tabel 3.

Daftar API

\begin{tabular}{|c|c|c|}
\hline Alamat & method & Hak Akses \\
\hline Log/in & Post & Guest \\
\hline Log/out & Post & Semua Pengguna \\
\hline Konfigurasi/rincian & Post & Administrator \\
\hline Konfigurasi/ubah & Post & Administrator \\
\hline User/daftar & Post & Administrator \\
\hline User/daftar_per_cmb & Post & Administrator \\
\hline User/rincian & Post & Semua Pengguna \\
\hline User/rincian/\$id & Post & Administrator \\
\hline User/tambah & Post & Administrator \\
\hline User/ubah & Post & Semua Pengguna \\
\hline User/ubah/\$id & Post & Administrator \\
\hline User/ubah_password & Post & Semua Pengguna \\
\hline User/ubah_password/\$id & Post & Administrator \\
\hline $\mathrm{CMB} /$ daftar & Post & $\begin{array}{l}\text { Administrator, } \\
\text { Direksi }\end{array}$ \\
\hline $\mathrm{CMB} /$ rincian/\$id & Post & $\begin{array}{l}\text { Administrator, } \\
\text { Direksi }\end{array}$ \\
\hline $\mathrm{CMB} /$ tambah & Post & Administrator \\
\hline $\mathrm{CMB} / \mathrm{ubah} / \$ \mathrm{id}$ & Post & Administrator \\
\hline Grup_debitur/daftar & Post & $\begin{array}{l}\text { Direksi, } \\
\text { Kepala WCR, } \\
\text { Kepala CMB, } \\
\text { Staff }\end{array}$ \\
\hline Grup_debitur/rincian/\$id & Post & $\begin{array}{l}\text { Direksi, } \\
\text { Kepala WCR, } \\
\text { Kepala CMB, } \\
\text { Staff }\end{array}$ \\
\hline Grup_debitur/tambah & Post & $\begin{array}{l}\text { Kepala WCR, } \\
\text { Kepala CMB, } \\
\text { Staff }\end{array}$ \\
\hline Grup_debitur/ubah/\$id & Post & $\begin{array}{l}\text { Kepala WCR, } \\
\text { Kepala CMB, } \\
\text { Staff }\end{array}$ \\
\hline Debitur/daftar & Post & Direksi, \\
\hline
\end{tabular}




\begin{tabular}{|c|c|c|}
\hline & & $\begin{array}{l}\text { Kepala WCR, } \\
\text { Kepala CMB, } \\
\text { Staff }\end{array}$ \\
\hline Debitur/daftar_per_grup_debitur & Post & $\begin{array}{l}\text { Direksi, } \\
\text { Kepala WCR, } \\
\text { Kepala CMB, } \\
\text { Staff }\end{array}$ \\
\hline Debitur/daftar_per_cmb & Post & Direksi \\
\hline Debitur/rincian/\$id & Post & $\begin{array}{l}\text { Direksi, } \\
\text { Kepala WCR, } \\
\text { Kepala CMB, } \\
\text { Staff }\end{array}$ \\
\hline Debitur/tambah & Post & $\begin{array}{l}\text { Kepala WCR, } \\
\text { Kepala CMB, } \\
\text { Staff }\end{array}$ \\
\hline Debitur/ubah/\$id & Post & $\begin{array}{l}\text { Kepala WCR, } \\
\text { Kepala CMB, } \\
\text { Staff }\end{array}$ \\
\hline Debitur/setujui/\$id & Post & $\begin{array}{l}\text { Kepala WCR, } \\
\text { Kepala CMB }\end{array}$ \\
\hline OTS/daftar & Post & $\begin{array}{l}\text { Direksi, } \\
\text { Kepala WCR, } \\
\text { Kepala CMB, } \\
\text { Staff }\end{array}$ \\
\hline OTS/rincian/\$id & Post & $\begin{array}{l}\text { Direksi, } \\
\text { Kepala WCR, } \\
\text { Kepala CMB, } \\
\text { Staff }\end{array}$ \\
\hline OTS/tambah & Post & $\begin{array}{l}\text { Kepala WCR, } \\
\text { Kepala CMB, } \\
\text { Staff }\end{array}$ \\
\hline OTS/ubah/\$id & Post & $\begin{array}{l}\text { Kepala WCR, } \\
\text { Kepala CMB, } \\
\text { Staff }\end{array}$ \\
\hline OTS/Setujui/\$id & Post & $\begin{array}{l}\text { Kepala WCR, } \\
\text { Kepala CMB }\end{array}$ \\
\hline Financial_ratio/daftar & Post & $\begin{array}{l}\text { Direksi, } \\
\text { Kepala WCR, } \\
\text { Kepala CMB, } \\
\text { Staff }\end{array}$ \\
\hline Financial_ratio/setujui/\$id & Post & $\begin{array}{l}\text { Kepala WCR, } \\
\text { Kepala CMB }\end{array}$ \\
\hline Financial_ratio/rincian/\$id & Post & $\begin{array}{l}\text { Direksi, } \\
\text { Kepala WCR, } \\
\text { Kepala CMB, } \\
\text { Staff }\end{array}$ \\
\hline Financial_ratio/tambah & Post & $\begin{array}{l}\text { Kepala WCR, } \\
\text { Kepala CMB, } \\
\text { Staff }\end{array}$ \\
\hline Financial_ratio/ubah/\$id & Post & $\begin{array}{l}\text { Kepala WCR, } \\
\text { Kepala CMB, } \\
\text { Staff }\end{array}$ \\
\hline Financial_ratio/setujui/\$id & Post & Kepala WCR \\
\hline Covenant/daftar & Post & $\begin{array}{l}\text { Direksi, } \\
\text { Kepala WCR, } \\
\text { Kepala CMB, } \\
\text { Staff }\end{array}$ \\
\hline Covenant/rincian/\$id & Post & $\begin{array}{l}\text { Direksi, } \\
\text { Kepala WCR, } \\
\text { Kepala CMB, } \\
\text { Staff }\end{array}$ \\
\hline Covenant/tambah & Post & $\begin{array}{l}\text { Kepala WCR, } \\
\text { Kepala CMB, } \\
\text { Staff }\end{array}$ \\
\hline Covenant/ubah/\$id & Post & $\begin{array}{l}\text { Kepala WCR, } \\
\text { Kepala CMB, } \\
\text { Staff }\end{array}$ \\
\hline Covenant/setujui/\$id & Post & Kepala WCR \\
\hline Covenant/konfirmasi/\$id & Post & Kepala WCR \\
\hline Covenant/Reminder/ & Post & $\begin{array}{l}\text { Direksi, } \\
\text { Kepala WCR, } \\
\text { Kepala CMB, } \\
\text { Staff }\end{array}$ \\
\hline Covenant/Reminder/\$id & Post & Direksi \\
\hline
\end{tabular}

\section{3) Presentation Layer}

Sedangkan pada Presentation layer terdapat tampilan yang berguna bagi pengguna. Pada layer ini data yang didapat dari logical layer ditampilkan sedemikian rupa agar dapat di baca dengan mudah oleh pengguna.

\section{UJI COBA DAN ANALISIS HASIL APLIKASI}

Pada bagian ini berisi tentang uji coba aplikasi terhadap hasil tersebut.

\section{A. Uji Coba Aplikasi}

Ketercapaian tujuan pembuatan aplikasi penentuan kebutuhan nutrisi harian ini dapat diketahui melalui pembuatan skenario uji coba. Skenario uji coba ini berupa uji verifikasi yang dilakukan sesuai dengan fungsional aplikasi yang diharapkan sehingga tahapan pengujiannya disesuaikan dengan alur proses dan scenario yang telah dibuat pada tahap perancangan aplikasi. Berdasarkan pada pelaksanaan uji coba aplikasi maka dapat dilihat bahwa aplikasi telah memenuhi semua fungsionalitas dan alur prosesnya.

Pada bagian ini dijelaskan mengenai pelaksanaan pengujian aplikasi sesuai skenario yang telah dijelaskan sebelumnya. Hasil uji coba ditunjukkaan pada tabel berikut ini.

Tabel 4.

Hasil uji coba

\begin{tabular}{|c|c|c|c|}
\hline No & Skenario & Hasil yang di harap & Status \\
\hline 1. & $\begin{array}{l}\text { Login dengan } \\
\text { username dan } \\
\text { password yang } \\
\text { benar }\end{array}$ & $\begin{array}{l}\text { Pengguna masuk ke } \\
\text { halaman sesuai } \\
\text { dengan level yang di } \\
\text { miliki }\end{array}$ & Berhasil \\
\hline 2. & $\begin{array}{l}\text { Pengguna gagal } \\
\text { login sebanyak } 3 \\
\text { kali }\end{array}$ & $\begin{array}{l}\text { Sistem meminta } \\
\text { masukan berupa } \\
\text { captcha }\end{array}$ & Berhasil \\
\hline 3. & $\begin{array}{l}\text { Pengguna } \\
\text { mengakses halaman } \\
\text { yang bukan haknya }\end{array}$ & $\begin{array}{l}\text { Sistem memindahkan } \\
\text { pengguna ke halaman } \\
\text { utama }\end{array}$ & Berhasil \\
\hline 4. & $\begin{array}{l}\text { Administrator } \\
\text { menambah } \\
\text { pengguna baru }\end{array}$ & $\begin{array}{l}\text { Terdapat pengguna } \\
\text { baru di daftar } \\
\text { pengguna }\end{array}$ & Berhasil \\
\hline 5. & $\begin{array}{l}\text { Administrator } \\
\text { menambah } \\
\text { pengguna dengan } \\
\text { username yang } \\
\text { sudah ada }\end{array}$ & $\begin{array}{l}\text { Muncul peringatan } \\
\text { gagal menambahkan } \\
\text { pengguna }\end{array}$ & Berhasil \\
\hline 6. & $\begin{array}{l}\text { Administrator } \\
\text { mengubah password } \\
\text { pengguna }\end{array}$ & $\begin{array}{l}\text { Muncu peringatan } \\
\text { berhasil mengganti } \\
\text { password }\end{array}$ & Berhasil \\
\hline 7. & $\begin{array}{l}\text { Administrator } \\
\text { mengubah password } \\
\text { pengguna, namun } \\
\text { password baru dan } \\
\text { konfirmasi } \\
\text { password tidak } \\
\text { sama }\end{array}$ & $\begin{array}{l}\text { Muncul peringatan } \\
\text { gagal mengganti } \\
\text { password }\end{array}$ & Berhasil \\
\hline 8. & $\begin{array}{l}\text { Administrator } \\
\text { menambah CMB } \\
\text { baru }\end{array}$ & $\begin{array}{l}\text { Muncul peringatan } \\
\text { berhasil } \\
\text { menambahkan } \mathrm{CMB} \\
\text { baru }\end{array}$ & Berhasil \\
\hline 9. & $\begin{array}{l}\text { Administrator } \\
\text { menambah CMB } \\
\text { baru dengan nama } \\
\text { yang sama dengan } \\
\text { yang sudah ada }\end{array}$ & $\begin{array}{l}\text { Muncul peringatan } \\
\text { gagal menambahkan } \\
\text { CMB baru }\end{array}$ & Berhasil \\
\hline 10. & $\begin{array}{l}\text { Administrator } \\
\text { mengubah nama } \\
\text { CMB }\end{array}$ & $\begin{array}{l}\text { Muncul peringatan } \\
\text { berhasil memperbarui } \\
\text { CMB }\end{array}$ & Berhasil \\
\hline 11. & $\begin{array}{l}\text { Administrator } \\
\text { mengubah nama } \\
\text { CMB dengan nama } \\
\text { yang sudah ada }\end{array}$ & $\begin{array}{l}\text { Muncul peringatan } \\
\text { gagal memperbarui } \\
\text { CMB }\end{array}$ & Berhasil \\
\hline 12. & $\begin{array}{l}\text { Staff menambah } \\
\text { Grup debitur baru }\end{array}$ & $\begin{array}{l}\text { Muncul peringatan } \\
\text { berhasil } \\
\text { menambahkan grup } \\
\text { debitur }\end{array}$ & Berhasil \\
\hline
\end{tabular}




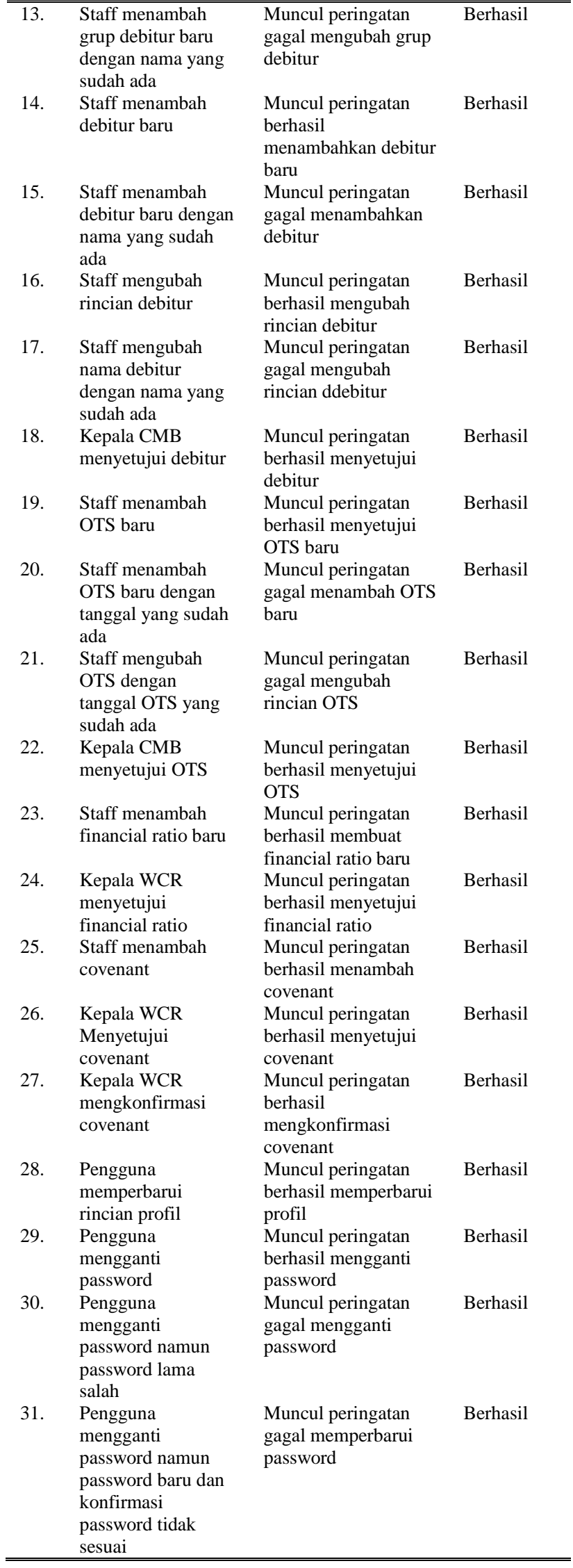

\section{KESIMPULAN DAN SARAN}

Berdasarkan proses-proses pengerjaan studi yang telah diselesaikan ini maka terdapat beberapa kesimpulan yang dapat diambil, diantaranya adalah: a. Sistem monitoring debitur memiliki fungsi untuk menyetujui rinican data dari debitur, rincian data yang telah di setujui menandakan data tersebut telah di periksa dan telah sesuai.

b. Sistem monitoring debitur memiliki fungsi konfirmasi untuk menandai covenant yang sudah dipenuhi oleh debitur

c. Sistem telah melalui pengujian fungsi, kemanan, compatibility, dan dibuat berdasarkan jaringan yang saat ini ada sehingga sistem dapat dan layak untuk diterapkan.

Aplikasi yang dibuat dalam Studi ini hanya dikhususkan untuk debitur pada segment wholesale saja, untuk debitur pada segment consumer maupun retail masih menggunakan proses yang saat ini ada di bank.

\section{DAFTAR PUSTAKA}

[1] I. B. Indonesia, Mengelola Kredir Secara Sehat. Gramedia Media Pustaka, 2014

[2] S. R. D. SETIAWAN, "Pertumbuhan kredit di 2016 capai 9 persen," Kompas, 2017. [Online]. Available: http://bisniskeuangan.kompas.com/read/2017/01/06/184755826/b i.pertumbuhan.kredit.di.2016.capai.9.persen.

[3] B. A. Pratama, "ANALISIS FAKTOR - FAKTOR YANG MEMPENGARUHI KEBIJAKAN PENYALURAN KREDIT PERBANKAN," Univ. DIPONEGORO, SEMARANG, 2010.

[4] R. S. N. I. WIDIASTUTI, "KAJIAN SISTEM MONITORING DOKUMEN AKREDITASI TEKNIK INFORMATIKA UNIKOM," majalah ilmiah UNIKOM.

[5] D. B. P. Y. Fauziah, "Pengembangan Sistem Informasi Perparkiran Menggunakan Arsitektur Three-tier," UPN, 2015

[6] Oracle, "What Are RESTful Web Services?," 2016. [Online] Available: http://docs.oracle.com/javaee/6/tutorial/doc/gijqy.html.

[7] "Introducing JSON," 2016. [Online]. Available: http://www.json.org/.

[8] S. IT, “DB-Engines Ranking," 2016. [Online]. Available: http://db-engines.com/en/ranking.

[9] O. Corporation, "MySQL Editions," 2016. [Online]. Available: https://www.mysql.com/products/. 